\title{
A case report of an infant with both left-sided gastroschisis and septo-optic dysplasia and literature review: possible shared etiology?
}

\begin{abstract}
The co-occurrence of gastroschisis and septo-optic dysplasia, two rare congenital anomalies of unknown etiology, has been reported in four cases. We report a fifth case, and the second where the gastroschisis was on the left side. The case involved a term infant with left-sided gastroschisis who was found to have optic nerve hyperplasia, diabetes insipidus, and hypothyroidism during her initial hospitalization. Gastroschisis and septo-optic dysplasia share some common risk factors, such as young maternal age, smoking, and illicit drug use. Providers should be aware of the potential for hypopituitarism and potential neuro developmental complications associated with gastroschisis, especially in the rare case where the gastroschisis is on the left side.
\end{abstract}

Volume 8 Issue 3 - 2018

\author{
Katherine Sullivan,' Daniel Croitoru, ${ }^{2}$ Samuel \\ Casella, ${ }^{2}$ Tyler Hartman, ${ }^{2}$ William Edwards ${ }^{2}$ \\ 'Assistant Professor of Pediatrics University of Massachusetts, \\ Worcester, England \\ ${ }^{2}$ Associate Professor of Surgery Geisel School of Medicine, \\ Dartmouth Hitchcock Medical Center, Lebanon
}

Correspondence: Katherine Sullivan, Assistant Professor of Pediatrics, Division of Neonatology, University of Massachusetts, UMass Memorial Medical Center,Worcester, MA, England,Tel 508-334-6083, Email katherine.sullivan@umassmemorial.org

Received: April 05, 2018 | Published: June 25, 2018

\section{Introduction}

Gastroschisis is a congenital abdominal wall defect with extrusion of the abdominal contents through a defect typically just to the right of the umbilicus. Gastroschisis has been associated with multiple risk factors but its pathogenesis remains unknown. There are theories that it is due to a vascular insult, with known associations of young maternal age, cigarette smoking, and illicit drug use. ${ }^{1,2}$ The incidence of gastroschisis is $\sim 5$ per 10,000 live births, and may be increasing. ${ }^{3}$ Left-sided gastroschisis is even rarer with only 18 reports found in our review of the literature. Septo-optic dysplasia (SOD) is a heterogeneous clinical disorder characterized by a combination of optic nerve hypoplasia, pituitary hormone abnormalities and midline brain defects. The incidence of SOD is not certain, but reported to likely be $\sim 1$ per 10,000 livebirths. ${ }^{4}$ These two seemingly unrelated congenital anomalies have several features in common. While the incidence of most congenital anomalies is directly correlated with maternal age, both of these anomalies are more common in younger mothers. ${ }^{1,5-7}$ They are also both postulated to be related to an insult around the 6th week of gestation. ${ }^{1,5-7}$ Co-occurrence of gastroschisis and septo-optic dysplasia has been reported 4 times, with the gastroschisis on the left side in one case. We present a second case of both left-sided gastroschisis and septo-optic dysplasia occurring in an infant girl.

\section{Case}

An infant girl weighing $2300 \mathrm{~g}$ was born at $374 / 7$ weeks gestational age to a 37 year old G5 P3 now P4 mother via cesarean section for a non-reassuring fetal heart tracing. Pregnancy had been uncomplicated. The mother denied any illicit drug use or smoking history. The infant was found on delivery to have a $3 \mathrm{~cm}$ abdominal wall defect to the left of the umbilicus. The entire midgut intestine and the distended bladder were eviscerated. The bowel was thickened, edematous, and matted with a meconium stained peel. The infant was placed in an occlusive plastic bag up to the torso, covering the defect and exteriorized bowel. The infant required no other specific interventions and had Apgar scores of 9 and 9. After post-delivery stabilization, the infant was sedated, paralyzed and incubated immediately prior to surgery. Primary closure of the gastroschisis was not possible due to extent of distention and thickening of the bowel. The intestinal contents were placed into a Silastic premade silo. The infant was extubated on post-operative day 1 to room air. The eviscerated bowel was slowly reduced over 13 days when final abdominal closure was performed. The infant passed her first meconium stool on DOL 22. On DOL 23 , her serum sodium was $148 \mathrm{mEq} / \mathrm{L}$; serum osmolality $309 \mathrm{mosm} / \mathrm{L}$; and urine osmolality $233 \mathrm{mosm} / \mathrm{L}$. Urine output at that time was $4 \mathrm{ml} / \mathrm{kg} / \mathrm{h}$ rand increased to a maximum of $9 \mathrm{ml} / \mathrm{kg} / \mathrm{hr}$ over the next several days. She was diagnosed to have diabetes insipidus. An MRI showed hypoplasia of the optic nerves and optic tracts and absence of the pituitary bright spot. The corpus callosum, cavum septum pellucidum and the optic chiasm were all present. Further investigation revealed hypothyroidism which was managed with levothyroxine. The MRI findings, pituitary hypoplasia and pituitary hormonal deficiencies satisfied criteria fora diagnosis of septo-optic dysplasia, a clinical diagnosis characterized by two or more of the following features: optic nerve hypoplasia, pituitary hypoplasia, and midbrain defects. ${ }^{7}$ She was discharged from the NICU on DOL 40 exclusively breastfeeding. Estradiol at 2 months of age and was below the normal range. She has normal development and growth and no other identified health issues at 4 months of age.

\section{Discussion}

Gastroschisis is a congenital full thickness abdominal wall defect with associated evisceration of the abdominal organs. The classic description is of a smooth edged defect typically smaller than $4 \mathrm{~cm}$ and almost always to the right of the umbilicus. ${ }^{8,9}$ It has an estimated incidence of 2-5/10,000 births and appears to be increasing over the past 20 years. ${ }^{8,10} \mathrm{~A}$ recent $\mathrm{CDC}$ report from 14 states showed 
an increased prevalence of 30\% between 1996-2005 (3.6/10,000) compared to $2006-2012(4.9 / 10,000) .{ }^{11}$ Gastroschisis is more common in younger mothers. ${ }^{1,2}$ Prevalence rates as high as 11.45 per 10,000 have been reported for mothers who are less than 20 years old compared with 0.51 per 10,000 for mothers 35 years and older. ${ }^{1,8} \mathrm{~A}$ lower BMI, smoking and drug use are all associated with an increased risk for having an infant with gastroschisis. ${ }^{1,2,12}$ Infection, particularly sexually transmitted infection during pregnancy was associated with higher risk of gastroschisis. ${ }^{1}$ At least some of these risks appear to be additive, the odds ratio for gastroschisis was very high $(26.5,95 \%$ CI 7.9-89.4) for malnourished mothers who smoked more than a pack/day 3 months before or during the first trimester. ${ }^{12}$ No definitive etiology of gastroschisis has been proven although several hypotheses have been proposed. These theories include a failure of mesoderm to form in the body wall during the 4th week of conception, rupture of the amnion around the umbilical ring, abnormal involution of the right umbilical vein, disruption of the omphalomesenteric artery, or abnormal folding of the body wall during embryogenesis..$^{13-15}$ However, none of these theories explain the full clinical presentation of gastroschisis. For example, they do not explain the unilateral nature of the lesion with a predominance of right-sided lesions and a few leftsided ones. The involution of the right umbilical vein, or occasionally the left umbilical vein, could explain the laterality of the lesion.

However in one report the ipsilateral umbilical vein was observed to be patent. ${ }^{16}$ Several of these theories implicate events occurring at a similar time in fetal life - between the 4-8th week of gestation. Left-sided gastroschisis is quite rare, ${ }^{9,14,17-20}$ but differs from the more common right-sided lesion in several ways. First, although the incidence of right-sided gastroschisis is similar between male and female infants, left-sided gastroschisis occurs more often in girls. ${ }^{9,14} \mathrm{In}$ our review of the literature, we found 18 reported cases of classic leftsided gastroschisis (Table 1). Of these, 12 were female; 4 were male; in 2 cases the sex was not reported. Extra-intestinal malformations were more common in cases of left-sided gastroschisis compared with right. ${ }^{14}$ Among those 19 cases (including the current case), the incidence of other malformations was $47 \%$, compared to an incidence of $32 \%$ reported for right-sided lesions. ${ }^{10}$ Septo-optic dysplasia is a clinical diagnosis characterized by two or more of the following features: optic nerve hypoplasia, pituitary hypoplasia, and midbrain defects. ${ }^{7}$ There is a wide spectrum of clinical disease severity.

The etiology of septo-optic dysplasia is currently unknown. Genetic abnormalities have only been identified in less than $1 \%$ of cases to date. $^{7}$ The association of pituitary and forebrain abnormalities have led to speculation that septo-optic dysplasia is a result of an injury between 4-6 weeks of gestation. ${ }^{7}$ Young maternal age and antenatal drug use are identified risk factors for septo-optic dysplasia, but the mechanisms by which they increase risk is unclear. ${ }^{5,13}$ Our patient is the fifth reported co-occurrence of gastroschisis and SOD, and the 2nd with where the gastroschisis was left sided. (Table 2) In 1981 Linarelli reported an infant with gastroschisis who developed diabetes insipidus on the 10th post-operative day. The infant was then found to have left cerebral atropy and septo-optic dysplasia. ${ }^{21}$ In 2008 Navti et al., ${ }^{22}$ reported a case of an infant who was born at 37 weeks with gastroschisis and schizencephaly. The infant was found to have sept-optic dysplasia on fundoscopy. The infant later developed diabetes insipidus, panhypopituitarism and generalized tonic clonic seizures..$^{22}$ In 2008 Suver et al., ${ }^{14}$ reported on three infants with leftsided gastroschisis. ${ }^{14}$ One of these also had septo-optic dysplasia and Panhypopituitarism. No mention was made about whether or not diabetes insipidus developed. In 2010, Kamien et al reported on a child with gastroschisis. ${ }^{23}$ The child was later found to have bilateral optic atrophy and panhypopituitarism with decreased ACTH, TSH, and diabetes insipidus. ${ }^{23}$ Gastroschisis is generally felt to be caused by an arrest or disruption of normal development, rather than genetically determined abnormal development.

Most co-existing anomalies, such as intestinal atresias, are considered to possibly be related to vascular or other disruption occurring at the same embryologic stage. Case reports that become a published part of the literature cannot accurately reflect incidence or associations of congenital anomalies. However, the reported co-occurrence of the two rare anomalies of gastroschisis and SOD raise the possibility of a common etiology. The over-representation of left-sided gastroschisis in reports of SOD and gastroschisis may be due to random chance and selective reporting of unusual combinations. However, it makes sense to proactively consider that babies with gastroschisis, particularly left-sided, may be at risk for developing endocrine complications associated with hypopituitarism, and neuro developmental complications associated with SOD.

Table I List of Cases of Infants with Left-sided Gastroschisis

\begin{tabular}{|c|c|c|c|c|c|c|}
\hline Case & Year & Authors & GA & Sex & $\begin{array}{l}\text { Associated } \\
\text { anomalies }\end{array}$ & $\begin{array}{l}\text { Maternal } \\
\text { age }\end{array}$ \\
\hline 1 & 1988 & Blair et al. ${ }^{\prime}$ & & & & \\
\hline 2 & 1989 & Hirthler et al & 27 & $\mathrm{~F}$ & & \\
\hline 3 & 1989 & Hirthler et al & "term" & M & & \\
\hline 4 & 1993 & Toth et al. ${ }^{18}$ & 35 & $\mathrm{~F}$ & & \\
\hline 5 & 2000 & $\begin{array}{l}\text { The } \\
\text { pcharoennirund }\end{array}$ & 37 & $\mathrm{~F}$ & & 20 \\
\hline 6 & 2000 & $\begin{array}{l}\text { The } \\
\text { pcharoennirund }\end{array}$ & 40 & $\mathrm{~F}$ & & 23 \\
\hline 7 & 2001 & Pringle et al & 34 & $M$ & & \\
\hline 8 & 2002 & Ashburn et al & 37 & $\mathrm{~F}$ & & \\
\hline 9 & 2004 & Yoshioka et al. ${ }^{17}$ & 38 & $\mathrm{~F}$ & & 20 \\
\hline 10 & 2004 & Orpen et al..$^{19}$ & "term" & $\mathrm{F}$ & $\begin{array}{l}\text { Pseudoextrophy } \\
\text { Pubic diastasis } \\
\text { Bifid clitoris } \\
\text { Double vagina } \\
\text { Anteriorly placed } \\
\text { anus } \\
\text { ASD }\end{array}$ & \\
\hline 11 & 2004 & Wang et al. ${ }^{16}$ & & & Situs inversus & \\
\hline 12 & 2006 & Gow et al. ${ }^{9}$ & 39 & $\mathrm{~F}$ & & 26 \\
\hline 13 & 2007 & Prasun et al & 24 & M & $\begin{array}{l}\text { Bilateral multicystic } \\
\text { kidneys }\end{array}$ & plastic \\
\hline 14 & 2008 & Suver et al. ${ }^{14}$ & 34 & $\mathrm{~F}$ & $\begin{array}{l}\text { Jejunal atresia } \\
\text { Microcolon } \\
\text { Septo-optic } \\
\text { dysplasia } \\
\text { Panhypopituitarism } \\
\text { Blindness } \\
\text { Absent corpus } \\
\text { callosum }\end{array}$ & \\
\hline 15 & 2008 & Suver et al. ${ }^{14}$ & 35 & $\mathrm{~F}$ & $\begin{array}{l}\text { AV malformations } \\
\text { involving the } \\
\text { posterior branches } \\
\text { of the external } \\
\text { carotid arteries, } \\
\text { tentorial veins and } \\
\text { dural sinuses and } \\
\text { stenosis of the } \\
\text { superior vena cava }\end{array}$ & \\
\hline 16 & 2008 & Suver et al. ${ }^{14}$ & 34 & $\mathrm{~F}$ & $\begin{array}{l}\text { ASD Pulmonic } \\
\text { stenosis }\end{array}$ & \\
\hline 17 & 2010 & Patel et al. ${ }^{4}$ & 34 & $\mathrm{~F}$ & Small left colon & 19 \\
\hline 18 & 2013 & Mandelia et al & "term" & M & & 20 \\
\hline 19 & 2015 & $\begin{array}{l}\text { Sullivan et al } \\
\text { (current) }\end{array}$ & 37 & $\mathrm{~F}$ & $\begin{array}{l}\text { Bilateral optic } \\
\text { Hypoplasia } \\
\text { Diabetes insipidus } \\
\text { Panhypopituitarism }\end{array}$ & 37 \\
\hline
\end{tabular}


Table 2 List of Cases of Infants with Both Gastroschisis and Septo-Optic Dysplasia

\begin{tabular}{|c|c|c|c|c|c|c|}
\hline Case & Reference & $\begin{array}{l}\text { Gestational } \\
\text { age (wk) }\end{array}$ & $\begin{array}{l}\text { Birth } \\
\text { weight }(\mathrm{g})\end{array}$ & Sex & Maternal Age (yr) & Findings described \\
\hline 1 & Linarelli² & 36 & 2700 & - & & $\begin{array}{l}\text { In utero vascular accident } \\
\text { Right-sided gastroschisis } \\
\text { Diabetes insipidus } \\
\text { Optic atrophy } \\
\text { Left cerebral hemisphere atrophy }\end{array}$ \\
\hline 2 & Navti ${ }^{22}$ & 37 & 2180 & $\mathrm{~F}$ & 19 & $\begin{array}{l}\text { Right-sided gastroschisis } \\
\text { Schizencephaly } \\
\text { Septo-optic dysplasia } \\
\text { Diabetes insipidus } \\
\text { Panhypopituitarism } \\
\text { Seizures }\end{array}$ \\
\hline 2 & Navti $^{22}$ & 37 & 2180 & $\mathrm{~F}$ & 19 & $\begin{array}{l}\text { Right-sided gastroschisis } \\
\text { Schizencephaly } \\
\text { Septo-optic dysplasia } \\
\text { Diabetes insipidus } \\
\text { Panhypopituitarism } \\
\text { Seizures }\end{array}$ \\
\hline 3 & Suver ${ }^{14}$ & 34 & - & $\mathrm{F}$ & & $\begin{array}{l}\text { Left-sided gastroschisis } \\
\text { Septo-optic dysplasia } \\
\text { Blindness } \\
\text { Panhypopituitarism } \\
\text { Absent corpus callosum }\end{array}$ \\
\hline 4 & Kamien $^{23}$ & - & - & - & 20 & $\begin{array}{l}\text { Right-sided gastroschisis } \\
\text { Bilateral optic atrophy } \\
\text { Hypoplasia of the optic chiasm } \\
\text { Panhypopituitarism } \\
\text { Diabetes insipidus } \\
\text { Grey matter heterotopia }\end{array}$ \\
\hline 5 & $\begin{array}{l}\text { Sullivan et } \\
\text { al (current) }\end{array}$ & 37 & 2300 & $\mathrm{~F}$ & 37 & $\begin{array}{l}\text { Left-sided gastroschisis } \\
\text { Bilateral optic Hypoplasia } \\
\text { Diabetes insipidus } \\
\text { Panhypopituitarism }\end{array}$ \\
\hline
\end{tabular}

\section{Acknowledgments}

None.

\section{Conflict of Interest}

The author declares there is no conflict of interest.

\section{References}

1. Baer RJ, Chambers CD, Jones KL, et al. Maternal factors associated with the occurrence of gastroschisis. Am J Med Genet A. 2015;167(7):15341541.

2. Haddow JE, Palomaki GE, Holman MS. Young maternal age and smoking during pregnancy as risk factors for gastroschisis. Teratology. 1993;47(3):225-228.

3. Jones AM. Increasing Prevalence of Gastroschisis-14 States, 19952012. MMWR Morbidity and Mortality Weekly Report. 2016; 65(2):2326.

4. Patel L, McNally RJ, Harrison E, et al. Geographical distribution of optic nerve hypoplasia and septo-optic dysplasia in Northwest England. $J$ Pediatr. 2006;148(1):85-88.

5. Feldkamp ML, Carey JC, Sadler TW. Development of gastroschisis: review of hypotheses, a novel hypothesis, and implications for research. Am J Med Genet A. 2007;143(7):639-652.

6. Garcia-Filion P, Borchert M. Optic nerve hypoplasia syndrome: a review of the epidemiology and clinical associations. Curr Treat Options Neurol. 2013;15(1):78-89.

7. Webb EA, Dattani MT. Septo-optic dysplasia. European Journal of Human Genetics. 2010;18(4):393-397.

8. Kirby RS, Marshall J, Tanner JP, et al. Prevalence and correlates of gastroschisis in 15 states, 1995 to 2005. Obstet Gynecol. 2013;122(2Pt1):275-281.
9. Gow KW, Bhatia A, Saad DF, et al. Left-sided gastroschisis. Am Surg . 2006;72(7):637-640.

10. Benjamin B, Wilson GN. Anomalies associated with gastroschisis and omphalocele: analysis of 2825 cases from the Texas Birth Defects Registry. J Pediatr Surg. 2014;49(4):514-519.

11. Jones AM. Increasing Prevalence of Gastroschisis-14 States, 19952012. MMWR Morbidity and Mortality Weekly Report. 2016; 65(2);2326

12. Valdéz JAL, Cóyotl DMC, Vega CAV. Pediatric Theme. Bol Med Hosp Infant Mex. 2011;68(3):224-231.

13. Lubinsky MS. Association of prenatal vascular disruptions with decreased maternal age. Am J Med Genet. 1997;69(3):237-239.

14. Suver D, Lee SL, Shekherdimian S, et al. Left-sided gastroschisis: higher incidence of extraintestinal congenital anomalies. Am J Surg. 2008;195(5):663-666.

15. Feldkamp ML, Carey JC, Sadler TW. Development of gastroschisis: review of hypotheses, a novel hypothesis, and implications for research. Am J Med Genet A. 2007;143(7):639-652.

16. Wang KS, Skarsgard ED. Left-sided gastroschisis associated with situs inversus. J Pediatr Surg. 2004;12;39(12):1883-1884.

17. Yoshioka H, Aoyama K, Iwamura Y, et al. Two cases of left-sided gastroschisis: review of the literature. Pediatr Surg Int. 2004;20(6):472473.

18. Tóth PP, Kimura K. Left-sided gastroschisis. J Pediatr Surg. 1993;28(12):1543-1544.

19. Orpen NM, Mathievathaniy M, Hitchcock R. Left-sided gastroschisis and pseudoexstrophy: a rare combination of anomalies. Pediatr Surg Int. 2004;20(7):551-552.

20. Patel R, Eradi B, Ninan GK. Mirror image left-sided gastroschisis. ANZ Journal of Surggery. 2010;80(6):472-473. 
21. Linarelli L. Neonatal Diabetes Insipidus Associated with Optic Atrophy, Cerebral Atrophy and Gastroschisis. Pediatric Research. 1981;15(12):1562-1562.

22. Navti O, Khare M, Potdar N, et al. P33. 09: Gastroschisis in association with schizencephaly and septo-optic dysplasia. A case report. Ultrasound in Obstetrics \& Gynecology. 2008;32(3):425-425.
23. Kamien B, Zankl A, Gabbett M. Septo-optic dysplasia and associations with amyoplasia and gastroschisis. Birth Defects Res A Clin Mol Teratol. 2010;88(6):497-501. 